\title{
Expression of the Tumor Necrosis Factor Receptor- Associated Factors (TRAFs) 1 and 2 is a Characteristic Feature of Hodgkin and Reed-Sternberg Cells
}

\author{
Keith F. Izban, M.D., Melek Ergin, M.D, Robert L. Martinez, B.A., HT(ASCP), Serhan Alkan, M.D. \\ Department of Pathology, Loyola University Medical Center, Maywood, Illinois
}

Tumor necrosis factor receptor-associated factors (TRAFs) are a recently established group of proteins involved in the intracellular signal transduction of several members of the tumor necrosis factor receptor (TNFR) superfamily. Recently, specific members of the TRAF family have been implicated in promoting cell survival as well as activation of the transcription factor NF- $\kappa$ B. We investigated the constitutive expression of TRAF1 and TRAF2 in Hodgkin and Reed-Sternberg (HRS) cells from archived paraffin-embedded tissues obtained from 21 patients diagnosed with classical Hodgkin's disease (HD). In a selective portion of cases, examination of HRS cells for Epstein-Barr virus (EBV)-encoded RNA was performed by in situ hybridization, and the results were compared with the magnitude of TRAF1 and TRAF2 staining. We also determined the TRAF profile in the classical HD cell lines L428, KMH2, and HS445 by Western blotting using a series of antibodies that specifically recognize the six individual TRAF family proteins (TRAF1-TRAF6). Moderate to high constitutive expression of TRAF1 and TRAF2 were found in 19 of 21 and 20 of 21 cases of classical HD, respectively. Of the remaining cases, one case showed weak expression of TRAF1, and another case showed weak expression of both proteins. No relationship was found between the staining intensity of the TRAF proteins and EBV expression in HRS cells. Strong constitutive expression of TRAF1 was also identified in the HD cell line L428, compared with the relatively weak expression observed in KMH2 and HS445. All three HD cell lines showed strong expression of TRAF2 protein and moderate, comparatively equal expression of TRAF4 and TRAF6. In contrast, TRAF3 was not expressed in

Copyright () 2000 by The United States and Canadian Academy of Pathology, Inc.

VOL. 13, NO. 12, P. 1324, 2000 Printed in the U.S.A.

Date of acceptance:

Address reprint requests to: Serhan Alkan, M.D., Department of Pathology, Loyola University Medical Center, EMS Building, Suite 2230, 2160 S.

First Avenue, Maywood, IL 60153; e-mail: salkan@luc.edu; fax: 708-327-2620. the HD cell lines. Although KMH2 showed weak expression, the remaining HD cell lines also lacked TRAF5 protein. These data demonstrate that constitutive expression of TRAF1 and TRAF2 is a characteristic feature of HRS cells from both patient and cell line specimens. Furthermore, with the exception of TRAF1 expression, HRS cells from the three HD cell lines showed similar TRAF protein expression patterns. Overall, these findings demonstrate the expression of several TRAF proteins in HD. Significantly, the altered regulation of selective TRAF proteins may reflect HRS cell response to stimulation from the microenvironment and potentially contribute both to apoptosis resistance and cell maintenance of HRS cells.

KEY WORDS: Hodgkin's disease, TRAF proteins, TNF, immunohistochemistry.

Mod Pathol 2000;13(12):1324-1331

In mammalian cells, the tumor necrosis factor (TNF) receptor-associated factor (TRAF) family consists of a group of six adapter proteins (TRAF1TRAF6) that participate in the intracellular signaling activity of several members of the TNF receptor (TNFR) superfamily, including the TNF receptor 2 (TNF-R2), CD30, CD40, the lymphotoxin- $\beta$ receptor, and the Epstein-Barr virus (EBV)-encoded latent membrane protein 1 (LMP1; 1-14). Structurally, TRAF proteins are composed of an $\mathrm{N}$-terminal cysteine/histidine-rich region containing zinc RING and/or zinc finger motifs, a central coiled coil region, and a C-terminal homology region that defines the TRAF family $(1,2,10,11,13)$. Significantly, the highly conserved C-terminal portion of the TRAF proteins, the TRAF domain, is capable of binding to the intracellular portions of TNF-R2, CD30, CD40, the lymphotoxin- $\beta$ receptor, and LMP1 (1, 2, 8, 10-13). Furthermore, recent investigations have shown that these members of the TNFR superfamily transduce signals regulating cell death and proliferation by interacting with TRAF1 (EBI6; 1, 4, 15), TRAF2 (TRAP; 1, 4-6, 14), TRAF3 
(CD40bp/LAP1/CRAF1; 1, 9, 16, 17), TRAF5 (1, 7, $14)$, or TRAF6 $(1,18)$. Alternatively, the function of other TNFR superfamily members, including TNF-R1 and Fas (CD95/APO-1), is not primarily mediated by TRAF protein binding. Instead, the effects of these receptors are mediated through association of their unique death domains with another group of molecules, including FADD/MORT1 $(19,20)$, TRADD $(21,22)$, RIP (23), and RAIDD/ CRADD (24).

Although studies addressing the origin and clonality of Hodgkin and Reed-Sternberg (HRS) cells have shown considerable heterogeneity, the pathobiological and clinical profiles of classical Hodgkin's disease (HD) have consistently correlated with the deregulated, high-level expression of various growth promoting cytokines, transcription factors, and cell surface receptors on HRS cells (25). Characteristically, HRS cells express many TNFR proteins, including TNF-R1, TNF-R2, CD30, CD40, and Fas (26-31). As mentioned previously, TNF-R2, CD30, and CD40 each contain TRAF binding motifs, through which intracellular signaling occurs via interaction with the TRAF proteins. Furthermore, in a significant portion of HD cases, HRS cells express the EBV protein LMP1 $(32,33)$. LMP1 also contains a TRAF-binding domain and uses TRAF proteins in some aspects of its intracellular signaling $(8,9,32$, 33).

Cell activation and apoptosis resistance promoted by TNFRs and mediated through TRAF protein interaction may influence the biological mechanisms of HRS cells. Recently, we and others have shown that constitutive expression of the transcription factor nuclear factor $\kappa \mathrm{B}(\mathrm{NF}-\kappa \mathrm{B})$ is vital for cell growth, proliferation, and resistance to apoptosis in HRS cells $(34,35)$. As seen in other cell systems, the NF- $\kappa$ B activation in HRS cells may be mediated by TRAF proteins via appropriate ligand stimulation of TNFRs found on the surface of HRS cells. Previous investigations have shown that in several cell types, overexpression of TRAFs 1, 2, 5, and 6 can induce activation of NF- $\kappa \mathrm{B}$, resulting in both cytokine secretion and resistance to apoptosis $(4-10,14,15$, 36). In contrast, overexpression of TRAF3 has been shown to inhibit NF- $\kappa \mathrm{B}$ signaling $(5,9)$. Investigation of TRAF protein expression in HRS cells, however, has been limited and has had somewhat heterogeneous results $(37,38)$. Interestingly, from one of these studies, Dürkop et al. (38) found a positive correlation between strong expression of TRAF1 transcripts and EBV expression in HRS cells.

In this investigation, we examined the expression patterns of the currently known TRAF proteins in HRS cells obtained from three established HD cell lines. We also determined whether constitutive expression of TRAF1 and TRAF2 are characteristic features of HRS cells obtained from HD cell lines and found in paraffin-embedded tissue samples from patients. As part of our evaluation of patient samples, we also compared the intensity of TRAF1 and TRAF2 staining with the expression of EpsteinBarr viral-encoded RNAs (EBERs) in HRS cells.

\section{MATERIALS AND METHODS}

\section{Patient Samples and Cell Lines}

Formalin-fixed, paraffin-embedded tissue sections from 21 cases of classical Hodgkin's disease were selected from the surgical pathology archives of Loyola University Medical Center for immunohistochemical determination of TRAF1 and TRAF2 expression. For each specimen, the diagnosis of HD was made retrospectively and confirmed by established histologic criteria (25). Fifteen cases demonstrated histologic features consistent with nodular sclerosis HD, with the remaining six cases classified as mixed cellularity HD.

The cell lines utilized in this study were derived from patients diagnosed with classical HD and include HS445, KMH2, and L428. The anaplastic large-cell lymphoma cell line SUDHL-1, the Jurkat T-cell lymphoma cell line, and the B-cell lymphoma cell line HBJ2 were used as controls. HS445 and Jurkat cell lines were obtained from the American Type Culture Collection (ATCC; Rockville, MD). The KMH2 and L428 cell lines were obtained from the German Collection of Microorganisms and Cell Cultures (Braunschweig, Germany). SUDHL-1 was generously provided by Dr. Steven Smith (Department of Pediatric Oncology, University of Kansas), and HBJ2 was a generous gift from Dr. Manuel Diaz (Cardinal Bernardin Cancer Center, Loyola University Medical Center). Cell lines were cultured in RPMI 1640 (Gibco-BRL, Grand Island, NY) supplemented with $20 \%(\mathrm{v} / \mathrm{v})$ heat-inactivated fetal bovine serum (Sigma, St. Louis, MO), $2 \mathrm{~mm}$ L-glutamine (Gibco-BRL), 25 mm HEPES (Sigma), 1 mm sodium pyruvate (Biofluids, Rockville, MD), 5.5 $\times 10^{-5}$ м 2-mercaptoethanol (Gibco-BRL), antibiotic-antimycotic solution (Sigma), and 50 $\mu \mathrm{g} / \mathrm{mL}$ gentamicin (Gibco-BRL). All cell lines were maintained at $37^{\circ} \mathrm{C}$ in a humidified incubator at $5 \%$ $\mathrm{CO}_{2}$.

Immunohistochemical Determination of TRAF1 and TRAF2 in HD Patient Samples

Four-micrometer-thick, formalin-fixed, paraffinembedded tissue sections from each case of classical HD were deparaffinized in xylene, hydrated in graded alcohol, and pretreated for antigen retrieval in $10 \mathrm{~mm} / \mathrm{L}$ citrate buffer, $\mathrm{pH} 6.0$, for 10 minutes. Staining was performed using antibodies that recognize TRAF1 (sc-6253, monoclonal mouse IgG, 
1:50 dilution, Santa Cruz Biotechnology, Santa Cruz, CA) and TRAF2 (sc-877, polyclonal rabbit IgG, 1:50 dilution, Santa Cruz Biotechnology). All staining runs were performed with a Ventana NEXES automated stainer (Ventana Medical Systems, Tucson, AZ) and a streptavidin-horseradish peroxidase detection kit (Ventana). The chromogen used was 3,3'-diaminobenzidine tetrahydrochloride (3,3'-diaminobenzidine).

Staining intensity was evaluated in each case, and the magnitude of staining in HRS cells was placed in one of four possible categories: $(-)=$ negative, $(+)=$ weak, $(++)=$ moderate, and $(+++)=$ strong staining intensity. In addition, the percentage of HRS cells demonstrating positive staining was estimated for each case.

\section{Epstein-Barr Virus In Situ Hybridization}

In situ hybridization (ISH) studies for EBV were performed on randomly selected formalin-fixed, paraffin-embedded tissues with the EBER-ISH kit (BioGenex, San Ramon, CA). Four-micrometerthick tissue sections were prepared on silanated glass slides, deparaffinized in xylene, hydrated in graded alcohol, and incubated with RNAse inhibitor (BioGenex). Tissues were then digested for 15 minutes with $10 \mu \mathrm{g} / \mathrm{mL}$ proteinase $\mathrm{K}$ (Boehringer Mannheim, Indianapolis, IN) at room temperature, rinsed in Tris-saline wash buffer with RNAse inhibitor for 5 minutes, and air dried for an additional 5 minutes. The probe consisted of biotin-labeled oligonucleotide in a hybridization solution consisting of $50 \%$ formamide, $2 \times$ standard saline citrate, and dextran sulfate. Probe and tissue were denatured simultaneously at $95^{\circ} \mathrm{C}$ for 10 minutes and incubated overnight at $37^{\circ} \mathrm{C}$ in a humidified chamber.

After the sections had been hybridized overnight, their cover slips were removed, and they were placed in a solution of $2 \times$ standard saline citrate for 5 minutes and washed twice with Tris-buffered saline ( $\mathrm{pH}$ 7.4) for 5 minutes. Hybridization detection was performed according to the manufacturer's instructions. The system consisted of sequential application of mouse antibiotin antibody, biotinylated antimouse immunoglobulin, and alkaline phosphatase-labeled streptavidin, followed by color development with BCIP/NBT chromogen/ substrate system (5-bromo-4-chloro-3-indolyl phosphate/nitroblue tetrazolium). Slides were scored as having positive or negative results.

\section{Western Blot Analysis of TRAF Protein Expression in HD Cell Lines}

Cells from each cell line were washed twice in cold PBS and lysed in CHAPS buffer. The soluble protein lysates obtained were then quantitated by using the Bio-Rad protein assay (BioRad, Hercules, CA). $50 \mu \mathrm{g}$ of protein were separated by $12.5 \%$ sodium dodecyl sulfate-polyacrylamide gel electrophoresis under reducing conditions and transferred to a nylon membrane. The membranes were blocked with 5\% nonfat milk in $20 \mathrm{~mm}$ Tris- $\mathrm{HCl}, \mathrm{pH}$ 7.6, $150 \mathrm{~mm} \mathrm{NaCl}$ (Tris-buffered saline) and stained with primary antibody for 2 hours at room temperature, followed by incubation with the appropriate horseradish peroxidase-conjugated secondary antibody (Jackson Immunoresearch Laboratories, West Grove, PA) for 1 hour at RT. Proteins were detected with an enhanced chemiluminescence (ECL) detection kit (Amersham Life Sciences, Arlington Heights, IL). Antibodies to proteins included the following: TRAF1 (sc-6253, monoclonal mouse IgG, Santa Cruz Biotechnology), TRAF2 (sc877, polyclonal rabbit IgG, Santa Cruz Biotechnology), TRAF3 (sc-947, polyclonal rabbit IgG, Santa Cruz Biotechnology), TRAF4 (sc-1921, polyclonal goat IgG, Santa Cruz Biotechnology), TRAF5 (sc6195, polyclonal goat IgG, Santa Cruz Biotechnology), and TRAF6 (sc-7221, polyclonal rabbit IgG, Santa Cruz Biotechnology).

\section{RESULTS}

\section{HRS Cells from Patient Samples of HD Demonstrate TRAF1 and TRAF2 Expression}

In all cases, HRS cells demonstrate immunopositivity for both TRAF1 and TRAF2 proteins; however, the magnitude of staining and the percentage of positive HRS cells showed some variability (Table 1). For TRAF1 staining, nine cases demonstrated strong immunopositivity concentrated predominantly in the cytoplasm; however, four of these cases showed nuclear staining as well (Figure 1A). Ten cases showed moderate TRAF1 staining within the cytoplasm; two cases, both classified as mixed cellularity HD, showed only weak TRAF1 expression. In 15 of $21(71 \%)$ cases, approximately $70 \%$ or more of HRS cells identified in the tissue sections showed immunopositivity for TRAF1. In all of these cases, TRAF1 expression was of moderate to strong intensity. Similar findings were seen for TRAF2 staining of HRS cells. Eight cases showed strong immunopositivity, with five of these cases demonstrating both cytoplasmic and nuclear staining (Figure 1B). Twelve cases showed cytoplasmic staining of moderate intensity, with additional nuclear immunopositivity in three cases. Only one case showed weak expression of both TRAF proteins. In all cases, $70 \%$ or more of HRS cells showed positive TRAF2 staining. 


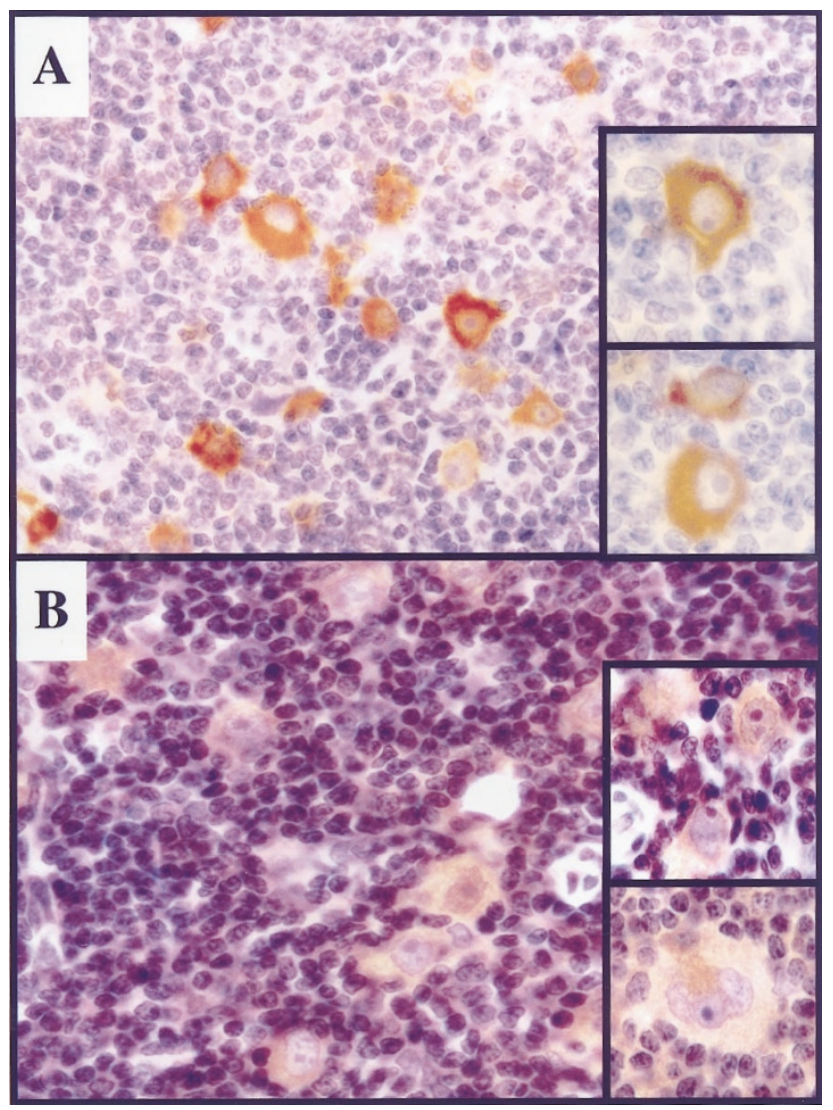

FIGURE 1. Tumor necrosis factor receptor-associated factor (TRAF) 1 and 2 staining in HRS cells from patient samples with Hodgkin's disease. In the great majority of cases, Hodgkin and Reed-Sternberg (HRS) cells showed moderate to strong expression of both TRAF1 and TRAF2 proteins. In the case demonstrated here, HRS cells show strong, predominantly cytoplasmic immunopositivity for TRAF1, with scattered cells showing nuclear expression as well (A, TRAF1, 100×; insert, $500 \times$ oil). A similar pattern of TRAF2 expression was also seen in this case (B,TRAF2, $400 \times$ ), with scattered HRS cells also demonstrating a Golgistaining pattern (B, TRAF2 insert, $500 \times$ oil).
Expression of TRAFs 1 and 2 Do Not Correlate with EBV-Encoded RNA in HRS Cells

Elsewhere, Dürkop et al. showed a positive correlation between strong expression of TRAF1 transcripts and EBV expression in cases of classical HD (38). To investigate the possibility of identifying a similar relationship in our HD cases, we compared the intensity of staining for TRAF1 and TRAF2 with the expression of EBER transcripts in HRS cells from 10 randomly selected patient cases (Table 1 ). EBER-positive cases were characterized by dark, uniform nuclear staining (Fig. 2). Although five of eight $(63 \%)$ EBER-positive cases showed strong TRAF1 and TRAF2 expression, three cases with either strong TRAF1 or TRAF2 expression and one case with strong expression of both TRAF proteins were negative for EBER transcripts. Furthermore in all EBER-negative cases, moderate to strong expression of both TRAF proteins was identified.

\section{HRS Cells from HD Cell Lines Demonstrate Similar TRAF Protein Profiles}

Expression of TRAFs 1-6 were examined by Western blotting of protein extracts from the HD cell lines HS445, L428, and KMH2 (Fig. 3). Although all three cell lines showed similar TRAF profiles, a notable difference in TRAF1 expression was seen between L428 and the other two HD cell lines. Markedly strong expression of TRAF1 (45 kD) was identified in L428 compared with the relatively weak expression observed in both $\mathrm{KMH} 2$ and HS445. TRAF1 analysis in the KMH2 and HS445 cell lines showed an additional slowly migrating band. This additional band most likely represents post-

TABLE 1. Expression of TRAF1, TRAF2, and EBER-ISH in HRS Cells from Patient Cases of Classical Hodgkin's Disease

\begin{tabular}{|c|c|c|c|c|c|c|}
\hline \multicolumn{2}{|c|}{$\begin{array}{c}\text { Case Number and } \\
\text { Classification }\end{array}$} & \multirow{2}{*}{$\begin{array}{c}\text { Percentage of HRS Cells } \\
\text { with TRAF1 Expression }\end{array}$} & \multirow{2}{*}{$\begin{array}{c}\begin{array}{c}\text { Intensity of TRAF1 } \\
\text { Staining* }\end{array} \\
+++ \text { N/C }\end{array}$} & \multirow{2}{*}{$\begin{array}{c}\text { Percentage of HRS Cells } \\
\text { with TRAF2 Expression }\end{array}$} & \multirow{2}{*}{$\begin{array}{c}\begin{array}{c}\text { Intensity of TRAF2 } \\
\text { Staining* }\end{array} \\
+++ \text { N/C }\end{array}$} & \multirow{2}{*}{$\begin{array}{r}\text { EBER-ISH } \\
\text { Negative }\end{array}$} \\
\hline 1 & NSHD & & & & & \\
\hline 2 & MCHD & 10 & + & 100 & + & ND \\
\hline 3 & MCHD & 80 & ++ & 100 & ++ & ND \\
\hline 4 & NSHD & 100 & +++ & 100 & ++ & Negative \\
\hline 5 & MCHD & 100 & + & 100 & ++ & ND \\
\hline 6 & MCHD & 80 & ++ & 80 & ++ & ND \\
\hline 7 & NSHD & 100 & +++ & 100 & ++ & Negative \\
\hline 8 & NSHD & 90 & +++ & 90 & +++ & Positive \\
\hline 9 & NSHD & 40 & ++ & 100 & $+++\mathrm{N} / \mathrm{C}$ & Negative \\
\hline 10 & MCHD & 80 & ++ & 90 & $++\mathrm{N} / \mathrm{C}$ & Positive \\
\hline 11 & NSHD & 100 & +++ & 100 & $+++\mathrm{N} / \mathrm{C}$ & Positive \\
\hline 12 & NSHD & 100 & $+++\mathrm{N} / \mathrm{C}$ & 100 & $+++\mathrm{N} / \mathrm{C} / \mathrm{G}$ & Positive \\
\hline 13 & NSHD & 100 & $+++\mathrm{N} / \mathrm{C}$ & 80 & $++\mathrm{N} / \mathrm{C} / \mathrm{G}$ & ND \\
\hline 14 & NSHD & 60 & ++ & 100 & $++\mathrm{N} / \mathrm{C}$ & ND \\
\hline 15 & MCHD & 50 & ++ & 80 & ++ & ND \\
\hline 16 & NSHD & 70 & ++ & 80 & $++\mathrm{G}$ & ND \\
\hline 17 & NSHD & 40 & ++ & 80 & ++ & ND \\
\hline 18 & NSHD & 70 & ++ & 70 & ++ & ND \\
\hline 19 & NSHD & 100 & +++ & 100 & $+++\mathrm{N} / \mathrm{C}$ & Positive \\
\hline 20 & NSHD & 80 & $+++\mathrm{N} / \mathrm{C}$ & 100 & +++ & Positive \\
\hline & NSHD & 50 & ++ & 100 & $+++\mathrm{G}$ & ND \\
\hline
\end{tabular}

NSHD, nodular sclerosis Hodgkin's disease; MCHD, mixed cellularity Hodgkin's disease; N/C, nuclear and cytoplasmic staining; G, Golgi staining; ND, not done. $(-)$, negative; $(+)$, weak positivity; $(++)$, moderate positivity; $(+++)$, strong positivity.

* All results indicate cytoplasmic staining unless otherwise stated. 


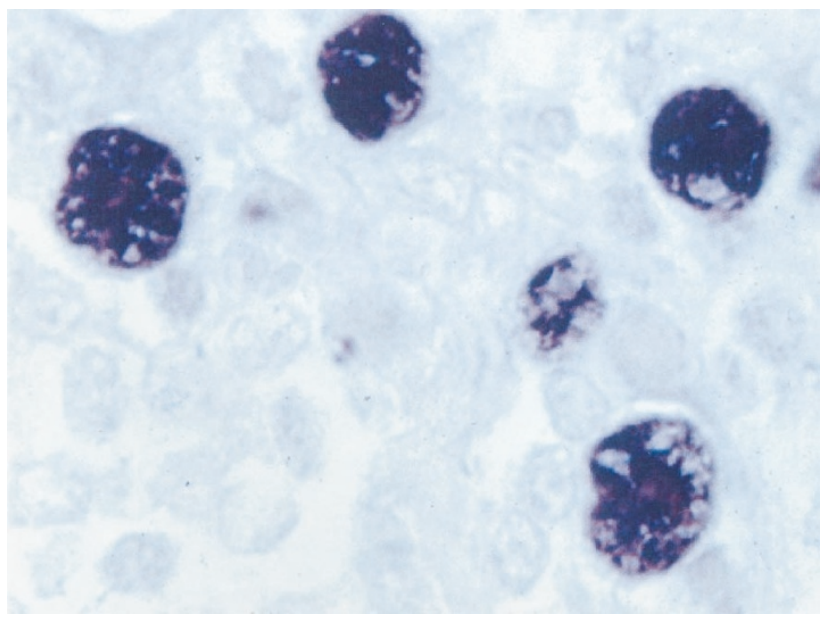

FIGURE 2. Expression of Epstein-Barr-encoded RNA (EBER) in Hodgkin and Reed-Sternberg (HRS) cells by in situ hybridization. In $60 \%$ of analyzed cases, HRS cells showed prominent nuclear positivity, as shown in this case of nodular sclerosis Hodgkin's disease (TRAF1 +++ ; TRAF2 +++ ); however, positive cases did not appear to correlate with the intensity of tumor necrosis factor receptor-associated factor staining. (EBER-ISH, 1000 oil $\times$ ).

translational modification or an association with another protein. Strong expression of TRAF2, moderate expression of TRAFs 4 and 6 , and absent expression of TRAF 3 were seen in all three cell lines. Only KMH2 showed weak expression of TRAF5.

\section{DISCUSSION}

Characteristically, HRS cells are known not only to produce numerous stimulatory cytokines but also to express a variety of cell surface receptors, including members of the TNFR superfamily. Using a variety of detection modalities, previous investigations have found only limited expression of TNFR1 and TNFR2 on HRS cells $(31,37)$. In contrast, however, abundant expression of CD30 and CD40 has been consistently identified in the great majority of HD cases (26-29, 31). Furthermore, in a significant portion of cases, HRS cells infected by EBV also commonly express LMP1 proteins $(32,33)$. Interestingly, HRS cells not only express TNFR proteins but also produce several ligands for these receptors as well, including TNF- $\alpha$, TNF- $\beta$, LT- $\alpha$, and CD30L $(26,28,29,37,39,40)$. Thus, HRS cells may be capable of autoamplifying TNFR stimulatory signaling via autocrine and paracrine receptorligand interaction. Interestingly, a recent investigation of Vener and colleagues (41) not only demonstrated the presence of TNF- $\alpha$ and TNFRs in the majority of HD patients but also showed that levels of TNF- $\alpha$ and related cytokines correlate with disease activity and clinical stage in these patients. Investigation of the downstream intracellular mediators that direct TNFR signaling in HD, however, has been limited $(37,38)$. Using a series of recently
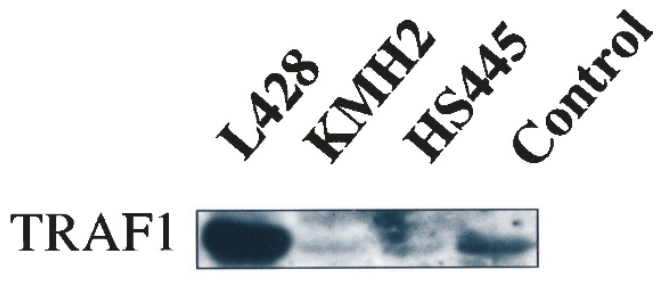

TRAF2
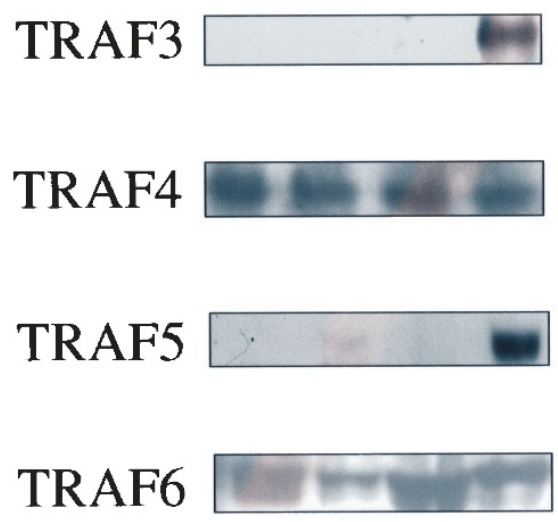

FIGURE 3. Tumor necrosis factor receptor-associated factor (TRAF) protein profiles of Hodgkin and Reed-Sternberg cells from Hodgkin's disease cell lines L428, KMH2, and HS445 as determined by Western blotting. All three cell lines showed similar expression patterns for the TRAF proteins, with the exceptions of strong TRAF1 expression, found only in L428 cells, and weak expression of TRAF5, specifically seen in KMH2. Strong TRAF2 expression, moderate TRAF4 and TRAF6 expression, and absence of TRAF3 expression were seen in all three cell lines. (Positive controls: SUDHL-1, TRAFs 1, 2, and 4; Jurkat T cells, TRAFs 3 and 6; HBJ2, TRAF5).

developed antibodies, we examined HRS cells from patient samples of HD for expression of TRAF1 and TRAF2 by immunohistochemistry. In addition, we also examined the profiles of all currently known TRAF proteins in three HD cell lines.

Only two previous investigations have addressed TRAF protein expression in HD, with variant results $(37,38)$. By micromanipulation and reverse transcription-polymerase chain reaction, Messineo et al. (37) examined single cells from five cases of classical HD and one case of nodular lymphocyte predominance HD. From this analysis, individual HRS cells showed highly heterogeneous expression of TRAF transcripts 1 to 3 . Of the 31 individual HRS cells obtained from classical HD cases, only 13 (42\%) were positive for TRAF1, whereas nine (29\%) HRS cells each were positive for TRAF2 or TRAF3, respectively (37). In contrast, Dürkop and colleagues (38) used in situ hybridization (ISH) to show moderate to strong expression of TRAF1 in the majority of HRS cells from patient cases of HD. Similarly, by immunohistochemistry, we also found consistent, moderate to strong expression of TRAF1 in HRS cells from histologic sections of HD. Analy- 
sis of TRAF1 expression in the three HD cell lines by Western blotting indicated quite variable intensities, with prominent, strong expression found in L428 cells and relatively weak, uniform expression found in both KMH2 and HS445. Interestingly, in contrast to the findings of Dürkop and colleagues (38), we found no significant correlation between strong TRAF1 (or TRAF2) immunopositivity and EBV-encoded RNA expression. Not only did all of the EBER-negative patient cases show moderate to strong expression of the TRAF proteins, but in addition, the EBV-negative HD cell line L428 showed abundant expression of TRAF1 as well. The difference between our study and that of Dürkop et al. may be related to the different methodologies used to detect TRAF1 in each study. Immunohistochemistry, as used in our study, identifies TRAF protein expression, rather than mRNA transcripts as detected by ISH or reverse transcription-polymerase chain reaction.

For the first time, we also observed moderate to strong immunopositivity for TRAF2 in HRS cells from patient cases and observed uniformly strong expression of TRAF2 in all three cell lines. Further analysis of the HD cell lines by Western blotting showed similar expression patterns for TRAFs 3 to 6 . Interestingly, we found moderate expression of TRAF4 in all three HD cell lines. Before this study, TRAF4 expression was thought to be restricted to breast carcinoma cells and, unlike the other TRAF proteins, was thought to be specifically found in the nucleus (42). The physiologic significance of TRAF4 expression, however, is unknown, and presently, TRAF4 is the only mammalian TRAF that has not been shown to associate with any of the known TNFRs. Similar to the case with TRAF4 expression, moderate expression of TRAF6 was also found in all HD cell lines. Interestingly, TRAF3 was not identified in the three HD cell lines, and only weak expression of TRAF5 was found in KMH2.

As shown by their ability to autonomously produce several stimulatory and growth-promoting cytokines, HRS cells characteristically exist in an activated state. Recently, we and others have shown that constitutive activation of NF- $\kappa \mathrm{B}$ is vital for cell maintenance and prevention of apoptosis in HRS cells $(34,35)$. Previous studies have shown that interaction of TRAFs $1,2,5$, and 6 with appropriate TNFRs induces activation of NF- $\kappa \mathrm{B}$ signaling $(4-10$, $14,15,36)$. On the basis of these previous studies, it is reasonable to speculate that constitutive activation of NF- $\kappa$ B in HRS cells may be mediated, at least in part, by TNFR/TRAF-driven mechanisms. As shown in this investigation, HRS cells from the majority of HD patient and cell line specimens demonstrate moderate to strong expression of TRAF1 and TRAF2, both of which have been implicated in NF- $\kappa \mathrm{B}$ activation via interaction with several
TNFRs. NF- $\kappa$ B activation by LMP1 was previously shown to be mediated by interaction with TRAF1/ TRAF2 heterodimers or by TRAF1 alone $(8,9)$. Hence, in HRS cells infected by EBV and demonstrating LMP1 proteins, these interactions may contribute significantly to constitutive NF- $\kappa$ B activation. More universally, however, HRS cells consistently demonstrate abundant surface expression of CD30 and CD40 (26-29, 31). Much like the case of LMP1, interaction of CD30 with TRAF1 and TRAF2 results in significant amplification of NF- $\kappa$ B signaling $(3,4,14)$. Similarly, stimulation of both CD40 and TNF-R2 also result in NF- $\kappa$ B activation mediated by TRAF2 $(5,6,13)$. Interestingly, TRAF6 protein, as found in all three of our HD cell lines, can also amplify NF- $\kappa$ B signaling via interaction with CD40 $(1,18)$. In contrast, TRAF3 overexpression has been shown to suppress both CD40- and TNF-R2-induced NF- $\kappa$ B activation (5, 37). Because of this finding, the apparent lack of TRAF3 expression in the three HD cell lines may also contribute to constitutive activation of NF- $\kappa \mathrm{B}$ in HRS cells; however, this possible relationship needs to be further investigated. Although TRAF5 have also been implicated in NF- $\kappa$ B activation $(7,14)$, HRS cells from the HD cell lines showed little (KMH2) or no expression of this protein. Overall, it is likely that one or several of these TRAF-mediated mechanisms contribute to the constitutive expression of NF- $\kappa \mathrm{B}$ in HRS cells.

In conclusion, our study demonstrated that both TRAF1 and TRAF2 expression are characteristic features of HRS cells from patient and cell line samples of HD. Furthermore, we also showed that similar TRAF protein profiles were found in each of the HD cell lines, with the exception of strong TRAF1 expression in L428 and weak TRAF5 expression in KMH2. Interestingly, HRS cells express TRAFs 1, 2, and 6, each of which has been correlated with NF- $\kappa \mathrm{B}$ activation through association with various TNFRs expressed on HRS cells. The exact mechanisms by which TNFR/TRAF interaction mediated $\mathrm{NF}-\kappa \mathrm{B}$ activation in HRS cells, however, remain undetermined. Additional studies addressing these possible relationships will likely provide valuable insights into the pathogenesis and progression of HD. Furthermore, the knowledge derived from these studies will likely create potential therapeutic opportunities for the treatment of HD and other neoplasms as well.

\section{REFERENCES}

1. Inoue J-I, Ishida $\mathrm{T}$, Tsukamoto $\mathrm{N}$, Kobayashi N, Naito A, Azuma S, et al. Tumor necrosis factor receptor-associated factor (TRAF) family: adapter proteins that mediate cytokine signaling. Exp Cell Res 2000;254:14-24.

2. Wallach D, Varfolomeev EE, Malinin NL, Goltsev YV, Kovalenko AV, Boldin MP. Tumor necrosis factor receptor 
and Fas signaling mechanisms. Annu Rev Immunol 1999;17: 331-67.

3. Lee SY, Lee SY, Kandala G, Liou M-L, Liou H-C, Choi Y. CD30/TNF receptor-associated factor interaction: NF- $\kappa$ B activation and binding specificity. Proc Natl Acad Sci U S A 1996;93:9699-703.

4. Duckett CS, Gedrich RW, Gilfillan MC, Thompson CB. Induction of nuclear factor- $\kappa \mathrm{B}$ by the CD30 receptor is mediated by TRAF1 and TRAF2. Mol Cell Biol 1997;17:1535-42.

5. Rothe M, Sarma V, Dixit VM, Goeddel DV. TRAF2-mediated activation of NF- $\kappa$ B by TNF receptor 2 and CD40. Science 1995;269:1424-6.

6. Lee HH, Dempsey PW, Park TP, Zhu X, Baltimore D, Cheng G. Specificities of CD40 signaling: involvement of TRAF2 in CD40-induced NF- $\kappa$ B activation and intercellular adhesion molecule-1 up-regulation. Proc Natl Acad Sci U S A 1999;96: 1421-6.

7. Nakano H, Oshima H, Chung W, Williams-Abbott L, Ware CF, Yagita $\mathrm{H}$, et al. TRAF5, an activator of NF- $\kappa \mathrm{B}$ and putative signal transducer for the lymphotoxin- $\beta$ receptor. J Biol Chem 1996;271:14661-4.

8. Devergne O, McFarland EC, Mosialos G, Izumi KM, Ware CF, Kieff E. Role of the TRAF binding site and NF- $\kappa$ B activation in Epstein-Barr virus latent membrane protein 1-induced cell gene expression. J Virol 1998;72:7900-8.

9. Devergne O, Hatzivassiliou E, Izumi KM, Kaye KM, Kleijnen MF, Kieff E, et al. Association of TRAF1, TRAF2 and TRAF3 with an Epstein-Barr virus LMP1 domain important for B-lymphocyte transformation: role in NF- $\kappa$ B activation. Mol Cell Biol 1996;16:7098-108.

10. Rothe M, Wong SC, Henzel WJ, Goeddel DV. A novel family of putative signal transducers associated with the cytoplasmic domain of the $75 \mathrm{kDa}$ tumor necrosis factor receptor. Cell 1994;78:681-92.

11. Song HY, Donner BD. Association of a RING finger protein with the cytoplasmic domain of the human type-2 tumour necrosis factor receptor. Biochem J 1995;809:825-9.

12. Sato T, Irie S, Reed JC. A novel member of the TRAF family of putative signal transducing proteins binds to the cytoplasmic domain of CD40. FEBS Lett 1995;358:113-8.

13. Hu HM, O’Rourke K, Boguski MS, Dixit VM. A novel RING finger protein interacts with the cytoplasmic domain of CD40. J Biol Chem 1994;269:30069-72.

14. Aizawa S, Nakano H, Ishida T, Horie R, Nogai M, Ito K, et al. Tumor necrosis factor receptor-associated factor (TRAF) 5 and TRAF2 are involved in CD30-mediated NF $\kappa$ B activation. J Biol Chem 1997;272:2042-5.

15. Carpentier I, Beyaert R. TRAF1 is a TNF inducible regulator of NF- $\kappa$ B activation. FEBS Lett 1999;460:246-50.

16. Cheng G, Cleary AM, Ye Z-S, Hong DI, Ledermann S, Baltimore D. Involvement of CRAF1, a relative of TRAF, in CD40 signaling. Science 1995;267:1494-8.

17. Brodeur SR, Cheng G, Baltimore D, Thorley-Lawson DA. Localization of the major NF- $\kappa \mathrm{B}$-activating site and the sole TRAF3 binding site of LMP-1 defines two distinct signaling motifs. J Biol Chem 1997;272:19777-84.

18. Ishida T, Mizushima S-I, Azuma S, Kabayashi N, Tojo T, Suzuki K, et al. Identification of TRAF6, a novel tumor necrosis factor receptor-associated protein that mediates signaling from an amino-terminal domain of the CD40 cytoplasmic region. J Biol Chem 1996;271:28745-8.

19. Chinnaiyan AM, O’Rourke K, Tewari M, Dixit VM. FADD, a novel death domain-containing protein, interacts with the death domain of Fas and initiates apoptosis. Cell 1995;81: 505-12.

20. Boldin MP, Varfolomeev EE, Pancer Z, Mett IL, Camonis JH, Wallach D. A novel protein that interacts with the death domain of Fas/APO1 contains a sequence motif related to the death domain. J Biol Chem 1995;270:7795-8.
21. Hsu H, Xiong J, Goeddel DV. The TNF receptor 1-associated protein TRADD signals cell death and NF- $\kappa$ B activation. Cell 1995;81:495-504.

22. Hsu H, Shu HB, Pan M-G, Goeddel DV. TRADD-TRAF2 and TRADD-FADD interactions define two distinct TNF receptor 1 signal transduction pathways. Cell 1996;84:299-308.

23. Stanger BZ, Leder P, Lee T-H, Kim E, Seed B. RIP: a novel protein containing a death domain that interacts with Fas/ APO-1 (CD95) in yeast and causes cell death. Cell 1995;81: 513-23.

24. Duan H, Dixit VM. RAIDD is a new "death" adapter molecule. Nature 1997;385:86-9.

25. Hsu SM, Hsu PL. The nature of Reed-Sternberg cells: phenotype, genotype, and other properties. Crit Rev Oncog 1994;5:213-45.

26. Gruss H-J, Brach MA, Drexler HG, Bonifer R, Mertelsmann $\mathrm{RH}$, Herrmann F. Expression of cytokine genes, cytokine receptor genes, and transcription factors in cultured Hodgkin and Reed Sternberg cells. Cancer Res 1992;52:335360.

27. Stein H, Mason DY, Gerdes J, O'Connor N, Wainscoat J, Pallesen G, et al. The expression of the Hodgkin's disease associated antigen $\mathrm{Ki}-1$ in reactive and neoplastic lymphoid tissue: evidence that Reed-Sternberg cells and histiocytic malignancies are derived from activated lymphoid cells. Blood 1985;66:848-58.

28. Gruss H-J, Herrmann F, Drexler HG. Hodgkin's disease: a cytokine producing tumor-a review. Crit Rev Oncog 1994; 5:473-538.

29. O'Grady JT, Stewart S, Lowrey J, Howie SE, Krajewski AS. CD40 expression in Hodgkin's disease. Am J Pathol 1994;144: 21-6.

30. Xerri L, Carbuccia N, Parc P, Hassoun J, Birg F. Frequent expression of FAS/APO-1 in Hodgkin's disease and anaplastic large cell lymphoma. Histopathology 1995;27:235-41.

31. Gruss H-J, Dower SK. Tumor necrosis factor ligand superfamily: involvement in the pathology of malignant lymphomas. Blood 1995;85:3378-404.

32. Herbst H, Dallenbach F, Hummel M, Niebobitek G, Pileri S, Stein H. Epstein-Barr virus latent membrane protein expression in Hodgkin and Reed-Sternberg cells. Proc Natl Acad Sci U S A 1991;88:4766-70.

33. Pallesen G, Hamilton-Dutoit SJ, Rowe M, Young LS. Expression of Epstein-Barr virus latent gene products in tumour cells of Hodgkin's disease. Lancet 1991;337(8737):320-2.

34. Bargou RC, Emmerich F, Krappmann D, Bommert K, Mapara MY, Arnold W, et al. Constitutive nuclear factor NF- $\kappa \mathrm{B}-$ Rel A activation is required for proliferation and survival of Hodgkin's disease tumor cells. J Clin Invest 1997;100: 2961-69.

35. Izban KF, Wrone-Smith T, Alkan S. Inhibition of NF- $\kappa \mathrm{B}$ induced apoptosis in Hodgkin's disease cell lines is independent of the cell death protease CPP32/Caspase 3. Mod Pathol 2001 (in press).

36. Darnay BG, Ni J, Moore PA, Aggarwal BB. Activation of NF- $\kappa \mathrm{B}$ by RANK requires tumor necrosis factor receptorassociated factor (TRAF) 6 and NF- $\kappa$ B inducing kinase. Identification of a novel TRAF6 interaction motif. J Biol Chem 1999;274:7724-31.

37. Messineo C, Jamerson MH, Hunter E, Braziel R, Bagg A, Irving SG, et al. Gene expression by single Reed-Sternberg cells: pathways to apoptosis and activation. Blood 1998;91: 2443-51.

38. Dürkop H, Foss H-D, Demel G, Klotzbach H, Hahn C, Stein $\mathrm{H}$. Tumor necrosis factor receptor-associated factor 1 is overexpressed in Reed-Sternberg cells of Hodgkin's disease and Epstein-Barr virus-transformed lymphoid cells. Blood 1999;93:617-23. 
39. Gruss H-J, Pinto A, Duyster J, Poppema S, Herrmann F. Hodgkin's disease: a tumor with disturbed immunological pathways. Immunol Today 1997;18:156-63.

40. Gruss H-J, Duyster J, Herrmann F. Structural and biological features of the TNF receptor and TNF ligand signals in the pathobiology of Hodgkin's disease. Annu Oncol 1996;7:19-26.

41. Vener C, Guffanti A, Pomati M, Colombi M, Alietti A, La Targia ML, et al. Soluble cytokine levels correlate with the activity and clinical stage of Hodgkin's disease at diagnosis. Leuk Lymphoma 2000;37:333-9.

42. Regnier CH, Tomasetto C, Moog-Lutz C, Chenard MP, Wendling C, Basset $\mathrm{P}$, et al. Presence of a new conserved domain in CART1, a novel member of the tumor necrosis factor receptor-associated protein family, which is expressed in breast carcinoma. J Biol Chem 1995;270: 25715-21.

\begin{abstract}
STATEMENT OF OWNERSHIP MANAGEMENT AND CIRCULATION (Required by 39 U.S.C. 3685)
1. Publication Title: Modern Pathology

2. Publication no.: 0893-3952. 3. Filing date: 10-01-00. 4. Frequency of issue: 12 times/year.

5. No. of issues published annually: $12 ; 6$. Annual subscription price: $\$ 235.00$.

7. Complete mailing address of known office of publication: Lippincott Williams \& Wilkins, 16522 Hunters Green Parkway, Hagerstown, MD 21740-2116. 8. Complete mailing address of the headquarters of general business offices of the publisher: 530 Walnut Street, Philadelphia, PA 19106.

9. Full names and complete mailing address of publisher editor and managing editor: Publisher: Lippincott Williams \& Wilkins Inc. 530 Walnut Street, Philadelphia, PA 19106; Editor: John N. Eble, M.D., M.B.A. Pathology (112 Roudebush VAMC), 1481 W. $10^{\text {th }}$ St., Indianapolis, IN 46202-2884. Managing Editor: Brenda M. Randall, Van Nuys Medical Science Building A-128, Indiana University School of Medicine, 635 Barnhill Drive, Indianapolis, IN 46202-5120. 10. Owner: United States and Canadian Academy of Pathology, Stephen Vogel, M.D., 3643 Walton Way Extension, Augusta, GA 30909

11. Known bondholders, mortgagees, and other security holders owning or holding $1 \%$ or more of total amount of bonds, mortgages, or other securities: None.

12. Purpose function, and nonprofit status: Has not changed during preceding 12 months.

13. Publication Name: Modern Pathology.

14. Issue Date for circulation data: Volume 13 , Issue 8

15. Extent and nature of circulation: Average number of copies each issue during preceding 12 months: (a) Total No. copies (Net Press Run), 6,463. (b) Paid and/or requested circulation; (1) Paid/Requested Outside-County Mail Subscriptions Stated on Form 3541. (Include advertiser's proof and exchange copies), 5,623; (2) Paid In-County Subscriptions (Include advertiser's proof and exchange copies), N/A; (3) Sales Through Dealers and Carriers, Street Vendors, Counter Sales, and Other Non-USPS Paid Distribution, N/A; (4) Other Classes Mailed Through the USPS, N/A. (c) Total Paid and/or Requested Circulation (Sum of $15 \mathrm{~b}$. (1), (2), (3), and (4) , 5623. (d) Free Distribution by Mail (Samples complimentary, and other free). (1) Outside-Country as Stated on Form 3541, 99; (2) In-country as Stated on Form 3541, N/A; (3) Other Classes Mailed Through the USPS, N/A. (e) Free distribution outside the mail (carriers or other means), none. (f) Total free distribution (sum of $15 \mathrm{~d}$ and 15e), 99. (g) Total distribution (Sum of 15c and 15f) 5,722. (h) Copies not distributed, 741. (i) Total (sum of $15 \mathrm{~g}$ and h), 6,463. (j) Percent Paid and/or Requested Circulation (15c divided by $15 \mathrm{~g}$ times 100), $98 \%$. No. copies of single issue published nearest to filing date: (a) Total no. copies (Net Press Run) 6.500. (b) Paid and/or requested circulation; (1) Paid/Requested Outside-country mail subscriptions stated on form 3541. (Include advertiser's proof and exchange copies) 61181 ; (2) Paid in-county subscriptions (include advertiser's proof and exchange copies, N/A: (3) Sales through dealers and carriers street vendors counter sales, and (include advertiser's proof and exchange copies, N/A; (3) Sales through dealers and carriers, street vendors, counter sales, and circulation (sum of $15 \mathrm{~b},(1),(2),(3)$, and (4)), 6,181 . (d) Free distribution by mail (samples, complimentary, and other free copies) 109. (e) Free distribution outside the mail (carriers or other means), none. (f) Total free distribution (sum of $15 \mathrm{~d}$ and $15 \mathrm{e}$ ) 109. (g) Total distribution (Sum of $15 \mathrm{c}$ and 15f), 6,290. (h) Copies not distributed: 210 . (i) Total (sum of $15 \mathrm{~g}$ and h), 6,500. (j) Percent Paid and/or Requested Circulation (15c divided by $15 \mathrm{~g}$ times 100 ), $98 \%$

16. This Statement of Ownership will be printed in volume 13, issue 12 of this publication

17. I certify that the statements made by me above are correct and complete.
\end{abstract}

